\title{
Corrigendum
}

\section{High-dose chemotherapy with autologous stem cell rescue in children with nephroblastoma}

B Kremens, B Gruhn, T Klingebiel, C Hasan, H-J Laws, E Koscielniak, B Hero, B Selle, C Niemeyer, FG Finkenstein, A Schulz, A Wawer, F Zintl and N Graf

Bone Marrow Transplantation (2003) 31, 1185. doi:10.1038/sj.bmt.1704068

Bone Marrow Transplantation 2003;31:893-898

The authors have realised that a wrong figure was included with the paper above. The correct figure is below (Figure 1).
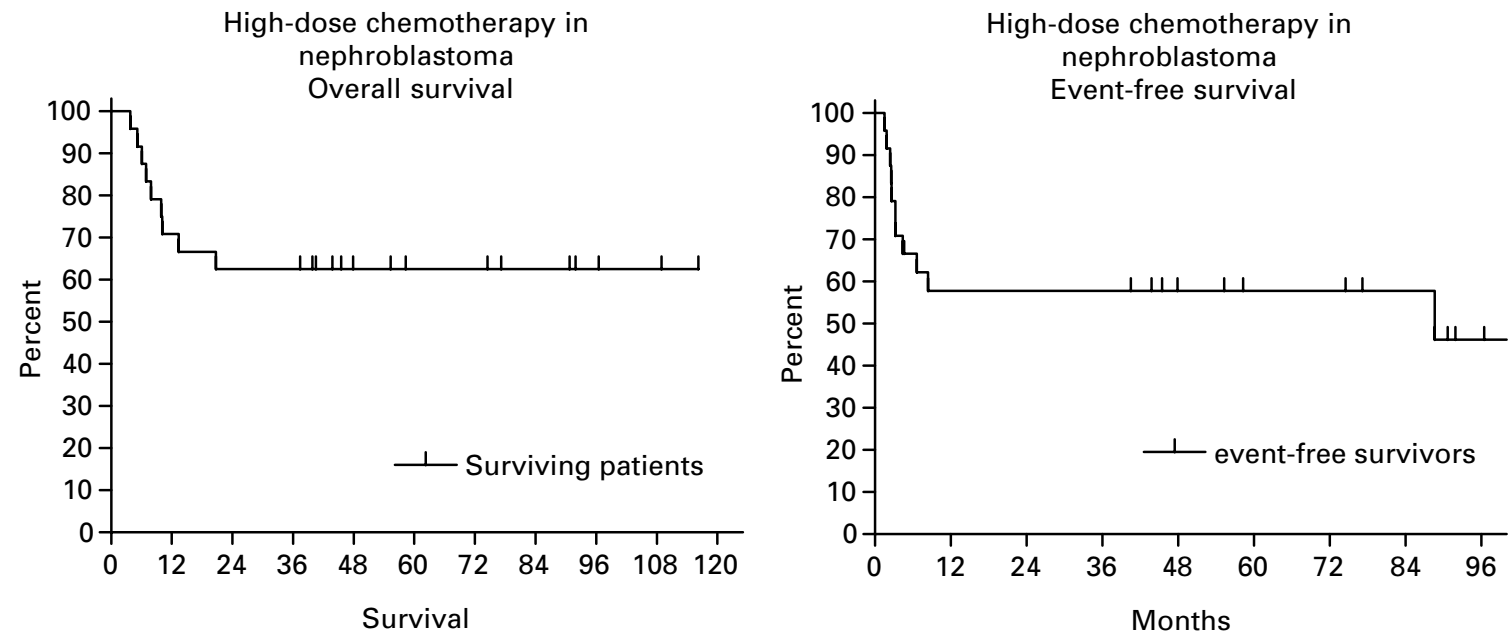

Figure 1 Survival and event-free survival estimates for 23 children with bad-risk nephroblastoma after high-dose chemotherapy 